\title{
Case Study of Major Depressive Disorder
}

\section{Muhammad Ejaz and Muhammad Zafar Iqbal*}

Hypnotherapist and Psychotherapist, Islamabad, Pakistan

\begin{abstract}
This document pertains to the case study of Major Depressive Disorder. The subject of the disorder was Mr. IR age 33 years, married, an MBA and was serving as manager in a government commercial bank. Mr. IR has one elder brother and an elder stepsister. He was referred to my clinic by an Ex-client. Mr. IR told me about the symptoms he was suffering from. These were; aggressive behavior, sadness, suicidal tendency, lack of interest in routine life matters, disillusionment about his sexual ability, disturbed sleep and at last a unique symptom that he kept sitting, talking and weeping in front of mirror for one or two hours once or twice in a week. He could not recall his actions afterwards which he used to play before mirror. Assessment made after taking semi-structured interviews from Mr.IR and his family. In light of assessment and DSM-IV, it was diagnosed that Mr. IR was suffering from Major Depressive Disorder.
\end{abstract}

Keywords: Depressive disorder; disillusionment; Aggressive behavior; Disturbed sleep

\section{Introduction}

Major purpose of this particular case study was to reaffirm and prove the efficacy of Fear-Stimuli Identification Therapy (FSIT) on empirical grounds. It was also intended to use FSIT in order to eliminate the symptoms of Major Depressive Disorder Mr. IR was suffering from as the therapy was already successfully used to remove the symptoms of various disorders in different cases.

\section{Hypotheses}

It is expected that the FSIT method would effectively cure the Major Depressive Disorder from which the above referred person Mr. IR is suffering.

\section{Method}

\section{Participants}

Mr. IR (client)

\section{Materials}

No any specific material used in this case study.

\section{Procedure}

In the first two sessions semi-structured interviews were conducted with Mr.IR and his family. Assessment made in the light of these interviews and reasons/causes for disorder were dug out. DSM-IV was consulted to decide the nature or type of disorder. In the subsequent eighty-eight sessions Mr.IR was asked to write on specific topics. Crossquestioning was carried out over the ideas mentioned in the writings.

\section{Results and Discussions}

\section{Results}

After diagnosis of Major Depressive Disorder, treatment was started in th3e light of FSIT method. Five sessions per week and a total of ninety sessions were conducted. In the course of treatment, her sister reported about Positive behavioral change in different spheres of Mr. IR's life. Clinical observations during treatment also indicated a gradual positive change in his personality. The difference between preassessment and post- assessment confirmed precision of hypotheses and efficacy of FSIT. Feedback was obtained on weekly basis for a period of three months from Mr. IR's family about any possible reappearance of symptoms of Major Depressive Disorder and this was confirmed that there was no reoccurrence of disorder's symptoms anymore.

\section{Discussions}

Before visiting my clinic Mr. IR had have already consulted different psychiatrists and was mostly treated by means of antidepressants. This had no significant effects upon client's disorder. Anyhow this medication helped Mr. IR sleep well as he was not able to sleep before it. Prior to write about intervention/treatment, a brief description of patient's social and family environment is necessary in order to understand the main causes of Mr. IR's disorder. Mr. IR's family consisted of mother, father, an elder brother and an elder stepsister. His grandmother also lived with Mr. IR's family. He started his schooling at the age of 5 years. His father was primary school teacher. His elder brother was also a student at the same school. He joined a religious school (Madrassa) also simultaneously. He was beaten frequently by his religious (Islamic) teacher. This resulted in some negative associations with religion and God in his unconscious level of mind. God and religion became stimulus for his fear instinct. He was always ambitious to develop acquaintance with his elder brother's friends circle, but his brother always discouraged him in this matter. At home, he rather suffered an unpleasant and troublesome situation. His mother and grandmother kept quarreling at home. He always supported this old lady used to take good care of him but at the same time this resulted in harsh reaction towards him by his mother. Even sometimes, the client was beaten up by his mother on the account of his favor to grandmother. Anyhow his step-sister and grandmother, both were a source of affection, security and love to him. His unconscious level of mind developed negative associations with loud voice and harsh behavior of his mother which also became stimulus for his fear instinct.

At the age of near about 06 years, he visited and stayed for one night at one of his relatives' home. In the night he was given bed in the room of his young uncle and his spouse. In the early night, his uncle started making love to his wife considering the little boy as sleeping. Whereas, the boy was not asleep and he noticed all the activity and watched the upper private parts of his uncle's wife who was continuously whispering

*Corresponding author: Muhammad Zafar lqbal, Hypnotherapist and Psychotherapist Islamabad, Pakistan, Tel: +92-3349585399; E-mail: iqbal_708@yahoo.com

Received June 14, 2015; Accepted January 19, 2016; Published January 22 2016

Citation: Ejaz M, Iqbal MZ (2016) Case Study of Major Depressive Disorder. J Clin Case Rep 6: 698. doi:10.4172/2165-7920.1000698

Copyright: (c) 2016 Ejaz M, et al. This is an open-access article distributed under the terms of the Creative Commons Attribution License, which permits unrestricted use, distribution, and reproduction in any medium, provided the original author and source are credited. 
to his husband to be careful as she feared that if the child would have been awaken by their noises. She said "take care of the child, he might awake and watch us" she also said that it would be a matter of great shame for both of us if the child awakes and watches us doing sex. On listening this, he thought of this activity as some sort of prohibited act which must be hidden from others. This was sudden and unexpected act which gripped the unconscious level of his mind. The second result of this act was this that watching her tight and young breasts (as the patient expressed to me during a session) played as stimulus for sexinstinct. After this act he developed the habit of attempting to watch the breasts of bathing ladies whenever he had a chance to do so. $\mathrm{He}$ also started to manage the pictures of ladies and actresses to satisfy his sex instinct. At the age of near about 15 years, while in class $9^{\text {th }}$, the client got the chance to watch the breasts of a young girl frequently who lived in adjacent house. The girl also responded him positively. He had chances to play with the breasts of that young girl. It is worth mentioning that the act of playing with breasts also worked as stimulus to fear-instinct as his unconscious level of mind always recalled the incident of watching the act of love making in his childhood as cited above.

In the course of playing with love, once the girl suddenly dropped her trousers down, became naked and asked the client to play sex with her. The young boy was shocked and fearful as his sex instinct was conditional with breasts but not with the intercourse. Rather he had been unconsciously fearful about orgasm as mentioned earlier. His whole body started shivering. At the same time the male organ of the boy erected for a while and then contracted instantly to its natural state. The reaction to the demand of intercourse by girl had a negative effect over the boy and he suddenly lost his interest in breasts even, for which he had a strong desire previously. His whole body sweated profusely. But the boy's counterpart was cunning one. She spontaneously gripped the situation and tried to calm down the boy. She gave him water and soothed the feared boy by tempted wordings. Then she asked the client to do nothing but only take off his trousers and lay down facing upward. The boy acted so, the girl got over the boy and both of them experienced a complete orgasm.

After this, a series of girls came in client's life as subservient to his sexual desire which was primarily based upon his severe interest to watch and play with the breasts. He never played an active role in sexual process; instead this always remained the responsibility of his counterpart. Actually this all was the repetition of his very first sexual experience with his neighbor girl as referred before and he played all this with his unconscious level of mind. It was the responsibility of the client's counterpart to make his male organ erected. At this stage his interest developed in body building. He regularly visited gymnasium to build up his body muscles. This resulted in an admiration by his mother. Client's mother appreciated the client for his strong and healthy body. He became more interested in body building in order to become blueeyed boy for his mother as he had bitter experience of mother's hatred in his childhood. He was married soon after his employment as bank officer. At first night, in the bed he encountered an untoward situation. Bride could not arouse the patient's sexual desire as her breasts were not stiff and hard. While in the past the client always made his choice in selecting the girls having more stiff and hard breasts in order to satiate his particular sex desire. He asked his wife to make him erect but she did not find it appropriate to do so. So there was no orgasm at the very first night of his married life. Client's wife left him after ten weeks.

Although he had sexual activities with many girls but fear instinct always remained active in his unconscious level of mind on account of his very first experience in his childhood when he watched the uncle with his wife during their orgasm process in night. He always took this act as morally prohibited and even religiously punishable by God. His second fear was associated with his own very first experience of intercourse with his neighbor girl which has developed a sense of erectile dysfunction in the client. He thought that he would always have to depend upon his counterpart for erection of his sex organ. He was very fond of friends' company in his childhood but at this juncture, he used to avoid social contacts and preferred to remain lonely. After his education, he was selected as bank officer as mentioned already. This added to his worries as he had to face people now.

\section{Assessment}

Major reasons/causes for disorder assessment were dug out on the basis of under mentioned main points picked from the discussion as detailed above:

In his childhood, the environment at home exerted adverse impact upon the client as his mother and grandmother always kept contending and quarreling at different issues. This contributed as stimulus to his fear-instinct. In later stages of his life loud sound of any woman was correlated to a quarreling situation by client's unconscious.

He considered the sexual intercourse as religiously and socially forbidden act as at the age of six years he had watched his young uncle and his spouse playing sex and during sexual act the woman continuously kept warning his husband to be silent and careful as if the boy (client) might be awaken and watch them doing sex.

His experience with his neighbor girl also contributed to his fear instinct as he was shocked by the sudden demand by that girl to play sex with her but on attempting to fulfill the desire of the girl, his male organ lost the erection and the girl had to work to make his organ erected again. This resulted in the feelings that he is always dependent upon his counterpart in the sexual act to make his male organ erected.

\section{Intervention}

Fear-Stimuli Identification Therapy (FSIT) is based upon the perception that some of the incidents (mostly the sudden incidents) in the early age of a child become stimuli for fear instinct which cast negative effects over the personality of a child and become reason for one or the other type of disorder.

FSIT investigates and digs out such events from a person's unconscious which play as stimuli for fear instinct. Whenever effected person encounters the events in his/her life resembling to the stimulus/ stimuli the specific incident which has stimulated the fear instinct previously, is recalled.

\section{Treatment}

After diagnosing that client is suffering from Major Depressive disorder, I started treatment which consisted of 88 sessions. The procedure of treatment adopted in this case is as under:-During first 7 sessions he was given with specific topics to write upon.

These topics were: (i) My mother, (ii) My father, (iii) My stepsister, (iv) My grandmother (v) My fears during childhood and (vi) General memory his age from 1 to 10 years.

In the first seven sessions of treatment, the patient was asked to write over the topics of his relationship with his mother and his general memory from one to ten years of age. On examining, it was found that a lot of words and sentences were crossed and rewritten. Moreover there was no logical sequence in the ideas mentioned in the writings. In the light of these writings, client was cross-questioned. During this 
process, the client expressed resistance to some of the questions and he felt an enormous burden over his shoulders and in the back of his head. He expressed aggressiveness and at some points he fell into drowsiness which is actually a symptom of avoidance. The writings by client about his mother and general memory of life from 1 to 10 years combined with the process of cross-questioning implied that client has an unconscious negative association with his mother.

In the eighth session, he was again asked to write on both of the topics. This time also there were a lot of misspelled words and cutting of sentences and words.

In the ninth session he was once again cross-questioned on the topic "Mother". This time the session of cross-questioning continued for four days. The reaction of the client during these sessions was same as mentioned above. This reconfirmed the idea that he has negative association and strong hatred to his mother in his unconscious. He knew consciously that mother is religiously and morally a very respectable personality, so he was forced by his unconscious to express his hatred in front of mirror in form of abusing and cursing his mother and God even. This fact was revealed during deep trance of hypnosis. It is worth mentioning that during all the course of treatment, only a single session of hypnosis was conducted because it seemed impossible to reveal the mystery of client's practice of sitting in front mirror as he had already told me about this practice. This hatred was a result of fear instinct stimulated by the violence of his mother against him in his childhood and the quarrels between his mother and grandmother.

In proceeding sessions same procedure was adopted for the other topics as already mentioned, in order to confirm about the unconscious negative/positive associations of client with his other relatives and associates as well as with sex. In the light of FSIT procedure, once the negative association/associations in the unconscious level of mind is/ are dug out, the repressed positive associations are brought into the conscious level of mind to balance the behavior. Chiefly, the reason for the development of negative association is fear instinct. Once the positive associations are brought into the conscious level of mind, they become empowered while previously lying in the unconscious level of mind they remain weak.

In the last sessions, the positive associations with mother and sex were explored from client's unconscious level of mind and were brought into conscious level of mind. In this way at the end of 90 sessions the patient was cured successfully and is now living a normal life [1].

\section{References}

1. American PsychiatricAssociation (2000) Diagnostic and statistical manual of mental disorders (4th edn.) 